\title{
Effect of gastric acid suppressants on human gastric motility
}

\author{
H P Parkman, J-L C Urbain, L C Knight, K L Brown, D M Trate, M A Miller, \\ A H Maurer, R S Fisher
}

\begin{abstract}
Background-The effect of histamine $\mathbf{H}_{2}$ receptor antagonists on gastric emptying is controversial.

Aims-To determine the effects of ranitidine, famotidine, and omeprazole on gastric motility and emptying.

Patients and methods-Fifteen normal subjects underwent simultaneous antroduodenal manometry, electrogastrography (EGG), and gastric emptying with dynamic antral scintigraphy (DAS). After 30 minutes of fasting manometry and EGG recording, subjects received either intravenous saline, ranitidine, or famotidine, followed by another 30 minutes recording and then three hours of postprandial recording after ingestion of a radiolabelled meal. Images were obtained every 10-15 minutes for three hours to measure gastric emptying and assess antral contractility. Similar testing was performed after omeprazole $20 \mathrm{mg}$ daily for one week.
\end{abstract}

Results-Fasting antral phase III migrating motor complexes (MMCs) were more common after ranitidine (9/15 subjects, $60 \%$ ), famotidine $(12 / 15,80 \%)$, and omeprazole $(8 / 12,67 \%)$ compared with placebo $(4 / 14,29 \%$; p<0.05). Postprandially, ranitidine, famotidine, and omeprazole slowed gastric emptying, increased the amplitude of DAS contractions, increased the EGG power, and increased the antral manometric motility index.

Conclusions-Suppression of gastric acid secretion with therapeutic doses of gastric acid suppressants is associated with delayed gastric emptying but increased antral motility.

(Gut 1998;42:243-250)

Keywords: gastric motility; gastric emptying; histamine $\mathrm{H}_{2}$ receptor antagonists; proton pump inhibitors; gastric acid secretion; scintigraphy

Gastric acid suppression with histamine $\mathrm{H}_{2}$ receptor antagonists has been reported to have variable effects on gastric motility and emptying. Studies have suggested an increase, ${ }^{12}$ no change, ${ }^{34}$ or a decrease in overall gastric emptying. ${ }^{5-7}$ Theoretically, gastric acid suppression may affect gastric emptying by several mechanisms. Diminished hydrolysis of solids because of acid suppression may delay solid phase gastric emptying. ${ }^{78}$ Acid suppression may increase serum levels of gastrin, ${ }^{9}$ a peptide known to slow gastric emptying. ${ }^{10}$ Removal of the normal braking action of acid in the duodenum could lead to an increase in gastric emptying. ${ }^{11-13}$ In addition, specific $\mathrm{H}_{2}$ receptor antagonists may also directly affect gastric motility. ${ }^{561415}$ In vitro, ranitidine, but not famotidine, has been reported to increase antral contractility by a cholinergic mechanism. ${ }^{16}{ }^{17}$

The aims of this study were twofold: to determine the effect of gastric acid suppression on gastric motility both in the fasting and postprandial periods; and to compare the effects of three different gastric acid suppressants (ranitidine, an $\mathrm{H}_{2}$ receptor antagonist with cholinergic properties; famotidine, an $\mathrm{H}_{2}$ receptor antagonist with minimal cholinergic effects; and omeprazole, a proton pump inhibitor without $\mathrm{H}_{2}$ receptor antagonist or cholinergic effects) on gastric motor function and emptying. Based on previous in vitro studies, ${ }^{16}$ we hypothesised that ranitidine, but not famotidine or omeprazole, would increase gastric motility and might accelerate gastric emptying.

\section{Materials and methods}

Fifteen normal volunteers were studied using a four way crossover design comparing the effects of placebo, ranitidine, famotidine, and omeprazole on gastric motility. On each study day, subjects underwent simultaneous antroduodenal manometry (ADM), cutaneous electrogastrography (EGG), and gastric emptying (GE) with dynamic antral scintigraphy (DAS). This protocol was approved by the Institutional Review Board and Radiation Protection Committee of Temple University.

\section{STUDY SUBJECTS}

Normal subjects were recruited for this project (10 men and five women, mean age 26.2 years, range 18-38 years). They were initially screened by telephone, and potential subjects underwent a medical history and physical examination. Exclusion criteria included prior gastrointestinal surgery (except appendectomy), the presence or history of gastrooesophageal reflux, peptic ulcer disease, irritable bowel syndrome, chronic gastrointestinal symptoms, or the use of any medications that might affect gastrointestinal motility. Women were studied only during the follicular phase (days 1-10) of the menstrual cycle. Pregnancy screening with serum $\beta$ human chorionic gonadotropin was performed on women on the morning prior to the start of each study.

STUDY PROTOCOL

Enrolled subjects were instructed to begin fasting at $10 \mathrm{pm}$ on the night prior to the study and
Accepted for publication 31 July 1997 
arrive at the research facility at $730 \mathrm{am}$. An antroduodenal manometry catheter was advanced transnasally to the ligament of Treitz (see below). Cutaneous EGG electrodes were placed (see below). The study day protocol included an initial 30 minute recording of fasting antroduodenal manometry and EGG prior to intravenous infusion of study drug. During the first three sessions, each subject received in random order: placebo (normal saline $5 \mathrm{ml}$ intravenous bolus then $50 \mathrm{ml} /$ hour intravenously), ranitidine ( $50 \mathrm{mg}$ intravenous bolus then $6.25 \mathrm{mg} /$ hour intravenously), or famotidine $(20 \mathrm{mg}$ intravenous bolus then 1.67 $\mathrm{mg} /$ hour intravenously). These doses of $\mathrm{H}_{2}$ receptor antagonists are those recommended for therapeutic dosing by intravenous infusion. ${ }^{18} 19$ The continuous infusion of study drug continued for the rest of the four hour recording period for that day. For the fourth session, each subject had been taking omeprazole, $20 \mathrm{mg}$ daily for one week; the last dose of omeprazole was taken just prior to placement of the antroduodenal catheter (approximately 2.5 hours prior to meal ingestion). For the omeprazole sessions, subjects received an intravenous infusion of saline, similar to the placebo studies.

After infusion of the bolus doses of test agents, fasting antroduodenal manometry and EGG recordings were continued for another 30 minutes. Longer recording times in the fasting period were not possible with the time constraints for the entire study. Each subject then ingested a technetium-99m sulphur colloid labelled solid meal with $300 \mathrm{ml}$ unlabelled water (see below). Three hours of postprandial recordings were then obtained using simultaneous ADM, cutaneous EGG, and GE with DAS. Static gamma camera images were obtained every 10-15 minutes to measure solid phase gastric emptying. Each static image was followed by dynamic, one second images for 256 seconds, for DAS which was synchronised with antral manometry and EGG recording.

At the end of the study day, a repeat fluoroscopic verification of manometry tube position was obtained, followed by removal of the manometry tube and EGG electrodes.

\section{Antroduodenal manometry}

An antroduodenal manometry catheter containing six solid state pressure transducers was used for these studies (Konigsberg Instruments, Inc., Pasadena, California). The three proximal transducers were $2 \mathrm{~cm}$ apart and the distal three transducers were $10 \mathrm{~cm}$ apart. ${ }^{20}$ The catheter was passed by nasal intubation into the stomach and positioned fluoroscopically through the pylorus into the duodenum so that the three proximal transducers were located in the distal antrum and the distal tip of the catheter usually at the ligament of Treitz. Antral and small bowel motility were recorded with a microDigitrapper (Synectics Medical, Inc., Irving, Texas).

\section{EGG recording}

Electrogastrography was performed as previously described. ${ }^{21}$ After placement of the antroduodenal manometry catheter, the abdominal skin surface for each recording site was carefully abraded until slightly erythematous (Buf-Puf Regular; 3M Personal Care Products, St Paul, Minnesota). If abdominal hair was present, this was removed with a razor. Three surface electrodes (Cleartrace electrodes; Medtronic Andover Medical, Inc., Haverhill, Massachusetts) were placed on the abdominal surface overlying the stomach. Two active electrodes were used: one electrode was placed on the midline of the abdomen, halfway between the umbilicus and the xyphoid process; the other was placed on the subject's left side, $1 \mathrm{~cm}$ below the bottom rib and a quarter of the distance towards the ventral midline. A reference electrode was placed on the left lower abdomen, below the umbilicus equidistant between each active electrode. Gastric myoelectric activity was recorded using the same Synectics microDigitrapper as used for antroduodenal manometry, thus data were acquired simultaneously. The sampling frequency for digital EGG recording was set at $4 \mathrm{~Hz}$.

Gastric and dynamic antral scintigraphy

Gastric scintigraphy was performed as previously reported ${ }^{223}$ with several modifications. Solid phase gastric emptying was evaluated after ingestion of a standardised test meal consisting of a ${ }^{99 \mathrm{~m}} \mathrm{Tc}$ sulphur colloid labelled egg sandwich (two large beaten eggs mixed with 74 $\mathrm{MBq}(2 \mathrm{mCi}){ }^{99 \mathrm{~m}} \mathrm{Tc}$ sulphur colloid, cooked on a Teflon non-stick griddle until firm and served between two pieces of toasted bread) with 300 $\mathrm{ml}$ of unlabelled water. This meal contains 1.18 MJ: $32 \%$ protein, $46 \%$ carbohydrate, $22 \%$ fat. Imaging for technetium counts $(128 \times 128$ pixel matrix) using a $140 \mathrm{Kev}$ photopeak with a $20 \%$ window was performed with the subjects in both the anterior and posterior standing positions for 30 seconds each every 10 minutes for one hour, then every 15 minutes for another two hours using a large field of view gamma camera (GE535, General Electric Medical Systems, Milwaukee, Wisconsin). In addition, after each static acquisition, dynamic acquisition (256 consecutive one second images; $64 \times$ 64 pixel matrix) in the anterior standing position was recorded to characterise antral contractions. $^{22}{ }^{24}$ The event marker on the microDigitrapper was used to record a time signal at the start of DAS recording to facilitate timing for later analysis of simultaneously acquired DAS, EGG, and ADM.

DATA ANALYSIS

Antroduodenal manometry

After the study was completed, the manometric and EGG data were downloaded from the microDigitrapper to a computer (NEC Powermate $\mathrm{SX} / 25 \mathrm{i}$ ). The fasting manometric tracings were inspected for the presence of phase III migrating motor complexes (MMCs) during both 30 minute periods before and after beginning study drug infusion. An antral phase III MMC was defined as the presence of at least two minutes of regular antral contractions at a frequency of 1-3 per minute, and associated in 
temporal sequence with phase III activity in the duodenum. $^{2025}$ For postprandial recordings, the most distal lead showing an antral pattern of contractility - that is, high amplitude pressure waves with frequencies of $0-4$ cycles per minute, was analysed. ${ }^{20}$ The distal small bowel pressure transducer was used for distal duodenal contractility. Postprandial antral and duodenal contractility were quantified as motility indexes calculated using computer software (Multigram 6.31B2H4, Gastrosoft, Irving, Texas). ${ }^{20}{ }^{23}$ Distal antral and duodenal motility indexes were calculated for each of the 256 second time periods corresponding to the DAS recordings. This motility index expresses the contractile activity as the natural logarithm of the area under the manometric pressure peaks above a threshold pressure of $9 \mathrm{~mm} \mathrm{Hg}$. The motility indexes (MI) were calculated using the formula: $\mathrm{MI}=\ln$ [area under the curve/ duration of recording]. An overall mean postprandial motility index was obtained by averaging the individual 4 minute 16 second MIs from the time period 0 to 180 minutes.

\section{Electrogastrography}

EGGs were analysed using computer software (Multigram 6.31B2H4, Synectics Medical, Inc., Irving, Texas) which employed fast Fourier transform (FFT) and running spectral analysis, as previously described ${ }^{21}$ with modifications to analyse smaller time periods throughout the study. Running spectral analysis was used for 15 minutes before drug infusion and 15 minutes after drug infusion. Each running spectrum was 4 minutes $16 \mathrm{sec}$ onds long, with the next spectrum advancing one minute, giving 3 minutes 16 seconds overlap between consecutive spectra. For the postprandial period, the FFT used a 4 minute 16 second spectrum of data starting at the time stamp entered to indicate the simultaneous acquisition of the DAS images. Use of $4 \mathrm{~Hz}$ sampling frequency and 4 minute 16 second spectra for the FFT gives a frequency resolution of $0.23 \mathrm{cpm}$.

The FFT results were expressed as power as a function of frequency, with the dominant frequency defined as the frequency with the highest power. ${ }^{2126}$ The dominant slow wave frequency and its power were determined for the fasting period, both before and after study drug infusion, and for each 256 second DAS acquisition time interval. In addition, the postprandial to fasting power ratio- that is, the ratio between the postprandial and fasting (prior to drug infusion) power of the dominant frequency, was computed for each DAS acquisition time interval. An overall mean postprandial EGG power ratio was obtained by averaging the individual power ratios from the time period 0 to 180 minutes.

\section{Gastric and dynamic antral scintigraphy}

Gastric emptying was analysed using conventional techniques. ${ }^{22}$ A region of interest was manually created to outline the entire stomach. Radioactive counts in the gastric region of interest were summed and corrected for isotope decay. The geometric mean of anterior and posterior counts was used to correct for attenuation (geometric mean counts $=$ square root [anterior counts $\times$ posterior counts]). Geometric mean counts were then expressed as a percentage of the maximal counts. Residual percent ${ }^{99 \mathrm{~m}} \mathrm{Tc}$ counts in the gastric region of interest were plotted against time to obtain time activity curves. The time to reach $50 \%$ retention $\left(t_{1 / 2}\right)$, the lag phase of the solid meal, and the emptying rate were determined by using computerised curve fitting techniques of the per cent retention versus time using a modified power exponential function $\mathrm{y}(\mathrm{t})=$ $100-100\left(1-e^{-k t}\right) \beta^{27}$ (Kaleidagraph 3.04, Synergy Software, Malvern, Pennsylvania) on Power Macintosh Computer (8100/80AV, Apple Computer, Cupertino, California). The parameters $\mathrm{k}$ and $\beta$ were determined by a nonlinear least squares fitting algorithm. Using this modified power exponential function, the lag phase is equal to $[\ln \beta] / \mathrm{k}$ and the slope of the terminal portion of the emptying curve is $\mathrm{k}^{27}$ Using this mathematical definition, the lag phase corresponds to the inflection point of the emptying curve at which the slope becomes constant. $^{27}$

Regional gastric emptying of the proximal stomach was performed by drawing regions encompassing the proximal and distal portions of the stomach as previously described. ${ }^{28}$ The proximal stomach was taken as the upper third of the stomach. The distal stomach was taken as the area of the stomach excluding the proximal stomach. Each region was outlined manually and decay corrected geometric mean counts for the proximal and distal stomach were expressed as a percentage of the maximum geometric mean counts in the total stomach and plotted versus time.

Dynamic antral scintigraphy was analysed by previously reported techniques. ${ }^{24}{ }^{29}$ In order to allow for precise outlining of the antrum, each set of dynamic images was first reframed in a single composite image. Three equal size regions of interest were drawn on the horizontal portion of the stomach between the incisura angularis and the pylorus to delineate the proximal, middle, and distal antrum. The time activity curves generated from proximal, middle, and distal regions of interest in the antrum were then analysed from the dynamic images using a refined Fourier transform to determine the dominant frequency and the amplitude of the antral contractile activity. A baseline restoration and normalisation of the raw antral time activity curves was first performed using a third degree polynomial fit. ${ }^{24}$ This helps eliminate artefacts due to patient or stomach translational movement and transforms the data in per cent change to the respective antral mean counts. An autocorrelation function was then applied to the normalised antral time activity curves. $^{24}$ This function helps eliminate background noise and non-periodic events in the defined time interval. The fast Fourier transform of the autocorrelated data was obtained to determine the dominant frequency (in contractions per minute) and the amplitude of the dominant frequency in each of the proximal, mid, and distal antral regions of interest. This 


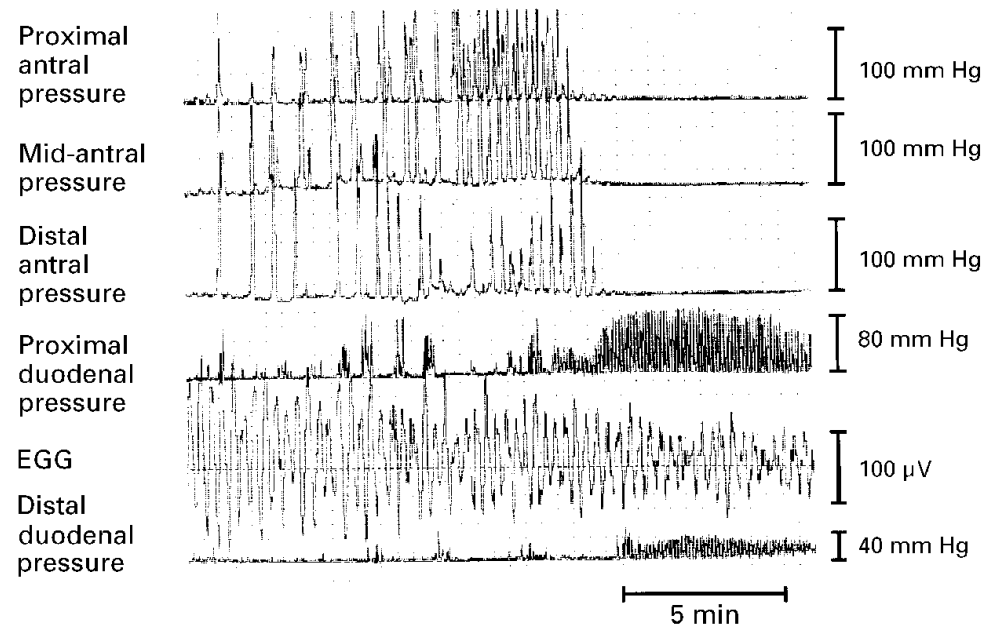

Figure 1 Fasting antroduodenal manometry and EGG recording. This tracing, taken during the fasting pattern, depicts a phase III MMC starting in the antrum and progressing distally into the duodenum.

Table 1 Effect of gastric acid suppressants on postprandial antroduodenal motility

\begin{tabular}{lllll}
\hline & $\begin{array}{l}\text { DAS amplitude } \\
(\%)\end{array}$ & $\begin{array}{l}\text { EGG power ratio } \\
\text { motility index }\end{array}$ & $\begin{array}{l}\text { Antral manometric } \\
\text { motility index }\end{array}$ & $\begin{array}{l}\text { Duodenal } \\
\text { motility index }\end{array}$ \\
\hline Placebo & $14.3(0.4)$ & $4.0(0.4)$ & $3.3(0.1)$ & $4.9(0.1)$ \\
Ranitidine & $15.8(0.4)^{\star}$ & $12.5(1.4)^{\star}$ & $4.3(0.1)^{\star}$ & $4.8(0.1)$ \\
Famotidine & $16.2(0.4)^{\star}$ & $22.8(3.8)^{\star}$ & $4.4(0.1)^{\star}$ & $4.7(0.1)$ \\
Omeprazole & $16.4(0.5)^{\star}$ & $18.2(1.8)^{\star}$ & $4.2(0.1)^{\star}$ & $4.9(0.1)$ \\
\hline
\end{tabular}

Results are expressed as mean (SEM).

${ }^{\star} \mathrm{p}<0.05 v$ placebo.

DAS amplitude represents the per cent variation of the normalised counts at the dominant frequency of antral contractions, and has been used as a non-invasive assessment of antral contractions. ${ }^{22} 24$ The overall DAS frequency and amplitude of antral contractions were taken as the average value of the proximal, mid, and distal antrum for each of the 256 second acquisition periods. An overall mean postprandial DAS contractile amplitude was obtained by averaging the individual DAS contractile amplitude from the time period 20 to $150 \mathrm{~min}$ utes.

$h(9)$

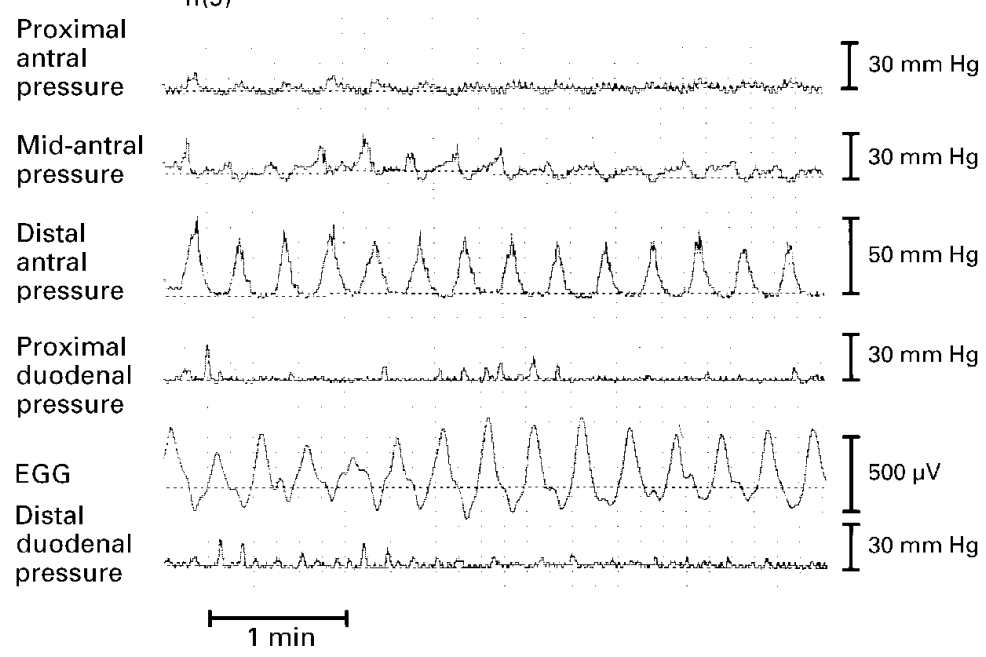

Figure 2 Postprandial antroduodenal manometry and EGG recording. In this tracing, prominent three cycle per minute antral contractile activity and three cycle per minute EGG activity are shown.
Processing of the static and dynamic data was performed on an 8200 Apple Power PC computer (Apple, Cupertino, California) with applications developed using Kaleidagraph (Abelbeck Software, Pennsylvania) and LabVIEW (National Instruments, Texas) software programs.

\section{STATISTICAL ANALYSIS}

Data are expressed as mean (SEM). The effects of each study drug on each motility parameter were assessed using $\chi^{2}$ analysis, Wilcoxon signed rank test, analysis of variance, or paired Student's $t$ test with Bonferroni adjustment for repeated measures. ${ }^{30}$ These statistical calculations were performed on a Macintosh Classic II computer using statistical software (Stat Works; Cricket Software, Inc., Philadelphia, Pennsylvania). Differences were considered statistically significant when the $\mathrm{p}$ value was less than 0.05 .

\section{Results}

All 15 subjects entered into the protocol underwent the first three studies investigating the effects of placebo, ranitidine, and famotidine. During the placebo session in one subject, the microDigitrapper malfunctioned, not allowing the data from the antroduodenal manometry and EGG to be recovered. Twelve of the 15 subjects successfully completed the omeprazole session; three subjects voluntarily withdrew.

EFFECTS OF GASTRIC ACID SUPPRESSANTS ON FASTING ANTRODUODENAL MANOMETRY

Figure 1 shows an example of antroduodenal manometry and EGG recording taken during the fasting period. The antroduodenal tracings in the fasting period for the 30 minute periods before and after study drug infusions were analysed for the presence of antral phase III MMCs. Antral phase III MMCs were significantly more common during ranitidine (9/15 subjects, $60 \%)$, famotidine $(12 / 15,80 \%)$, and omeprazole $(8 / 12,67 \%)$ administration compared with placebo $\left(4 / 14,29 \% ; \mathrm{p}<0.05\right.$ by $\chi^{2}$ analysis).

EFFECTS OF GASTRIC ACID SUPPRESSANTS ON POSTPRANDIAL ANTRODUODENAL MOTILITY Antroduodenal manometry

Figure 2 shows recordings of postprandial antroduodenal manometry and electrogastrography. Figure 3 shows the postprandial antral motility indexes over time for each of the treatment groups. There was a significant $(p<0.01)$ increase in the mean overall three hour postprandial antral motility index with each of the three acid suppressants: ranitidine (4.3 (0.1)), famotidine (4.4 (0.1)), and omeprazole (4.2 (0.1)), compared with placebo (3.4 (0.1)) (table 1$)$. There was no significant difference in the postprandial duodenal motility index for any of the drug regimens compared with placebo (table 1).

\section{Electrogastrography}

The EGG signals (lead 5 in figs 1 and 2) were analysed for fasting and postprandial time 


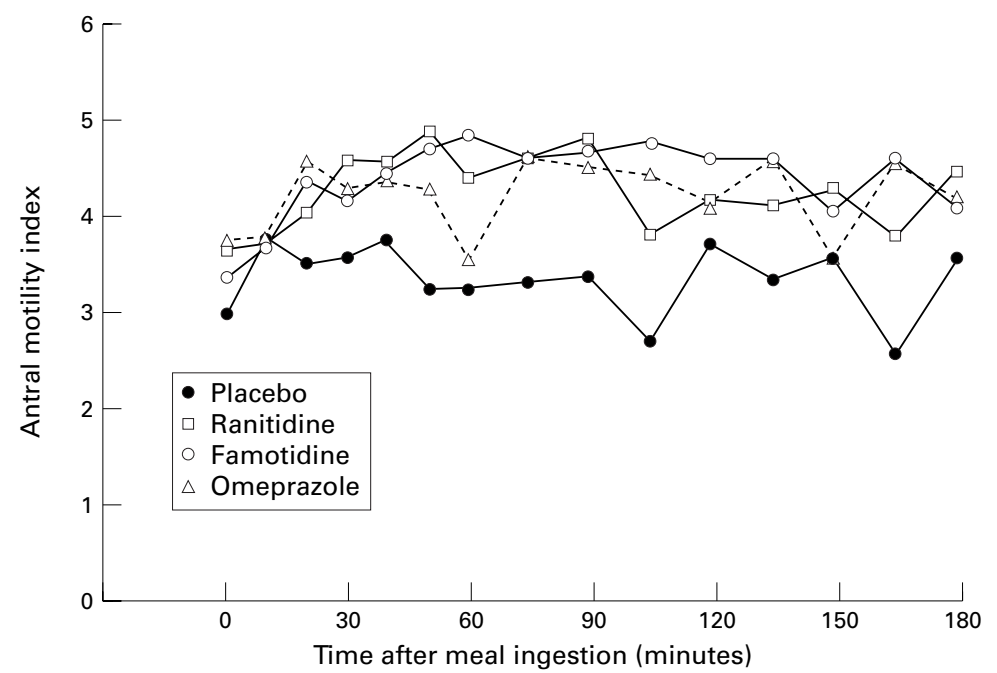

Figure 3 Effects of gastric acid suppressants on postprandial antral motility indexes.

periods by fast Fourier transform analysis to obtain a dominant frequency and power of the dominant frequency. There was an initial decrease in EGG dominant frequency after meal ingestion for all treatment groups. In the placebo study the initial fasting dominant frequency of $2.94(0.05) \mathrm{cpm}$ transiently decreased to $2.70(0.10) \mathrm{cpm}(\mathrm{p}<0.01)$ after meal ingestion and rapidly returned to a three cycle per minute pattern for the rest of the postprandial recording. The frequency of the EGG during administration of the three gastric acid suppressants was no different from placebo.

EGG power increased significantly after meal ingestion with each of the four treatment arms of the study. The ratio of the power of the postprandial dominant frequency to the power of the fasting dominant frequency (the EGG power ratio) increased significantly for each of the three gastric acid suppressants compared with placebo (table 1). There was no statistically significant difference among the three gastric acid suppressants.

Gastric emptying scintigraphy

Gastric emptying curves, expressed as per cent retention over time, were similar for the initial part of the study for placebo, ranitidine, famotidine, and omeprazole (fig 4A). After $60 \mathrm{~min}-$ utes, the curves diverged; there was significantly more retention for ranitidine, famotidine, and omeprazole compared with placebo. At two hours after meal ingestion, gastric retention was 46 (4)\% for ranitidine, 41 (5) $\%$ for famotidine, and 46 (13) $\%$ for omeprazole compared with 27 (4)\% for placebo $(p<0.01$; table 2$)$. Similarly, the half emptying times for ranitidine, famotidine, and

Table 2 Effect of gastric acid suppressants on gastric emptying scintigraphy

\begin{tabular}{lllll}
\hline & $\begin{array}{l}\text { Per cent remaining at } \\
2 \text { hours }\end{array}$ & $t^{1 / 2(\text { min })}$ & Lag phase (min) & Slope (k) (min-1) \\
\hline Placebo & $27(4)$ & $78(5)$ & $46(4)$ & $0.017(0.002)$ \\
Ranitidine & $46(4)^{\star}$ & $113(10)^{\star}$ & $57(6)$ & $0.012(0.001)^{\star}$ \\
Famotidine & $41(5)^{\star}$ & $103(8)^{\star}$ & $47(7)$ & $0.012(0.001)^{\star}$ \\
Omeprazole & $46(4)^{\star}$ & $107(8)^{\star}$ & $48(10)$ & $0.011(0.001)^{\star}$ \\
\hline
\end{tabular}

Results are expressed as mean (SEM).

${ }^{\star} \mathrm{p}<0.05 v$ placebo. omeprazole were significantly greater than for placebo (table 2). This delay was associated with similar lag phases for the four groups, whereas the slopes of the emptying curves were significantly less for ranitidine, famotidine, and omeprazole than for placebo (table 2).

The delay in gastric emptying was further evaluated using regional gastric emptying analysis. The emptying of the proximal stomach was similar for the four study groups (fig $4 \mathrm{~B})$. In contrast, meal retention in the distal stomach was increased for ranitidine, famotidine, and omeprazole compared with placebo (fig 4C). At 120 minutes, the values for ranitidine $(39.1$ (2.6)\% retention), famotidine (35.6 (3.5)\%), and omeprazole (40.6 (3.1)\%) were greater than that for placebo (20.2 (2.7)\% retention). Using analysis of variance, these numbers are significantly different $(\mathrm{p}<0.01)$.

\section{Dynamic antral scintigraphy}

For analysis of antral contractility using dynamic acquisition, three regions of interest from the proximal, mid, and distal antral regions were designated, and the counts over time were quantified for each region. The results of the DAS are interpreted only for the 20 to 150 minute postprandial periods due to low counts in the antrum at other times. In the early portion (times 0 and 10 minutes), not enough counts had arrived in the antrum; and in the later phase (times 165 and 180 minutes), there were too few counts in the antrum as a result of gastric emptying. Figures $5 \mathrm{~A}$ and $5 \mathrm{~B}$ show examples of these time activity curves from the mid-antral region of interest. The phasic counts represent the contracting antrum. Using fast Fourier transform analysis expressing amplitude as a function of frequency, the dominant frequency is represented by the peak with the highest amplitude (figs 5C and 5D). This DAS amplitude represents the per cent variation of the normalised counts at the dominant frequency of antral contractions. There were no differences in the DAS dominant frequency observed over time with the three acid suppression agents, compared with placebo. In contrast, the DAS amplitude of contractions increased significantly for each of the three gastric acid suppressants corresponding to the increase in EGG power and antral manometric motility index (table 1 ).

\section{Discussion}

This study has shown that therapeutic doses of ranitidine, famotidine, and omeprazole, which suppress gastric acid secretion, affect both gastric motility and gastric emptying. All significantly delayed gastric emptying despite an increase in postprandial antral contractility as assessed using antral manometry, electrogastrography, and dynamic antral scintigraphy. Interestingly, these agents also significantly stimulated antral phase III MMCs in the fasting state.

The observation that during fasting, gastric acid suppression with each of the agents, ranitidine, famotidine, and omeprazole, was associated with an increased occurrence of antral phase III MMCs suggests that gastric acid 

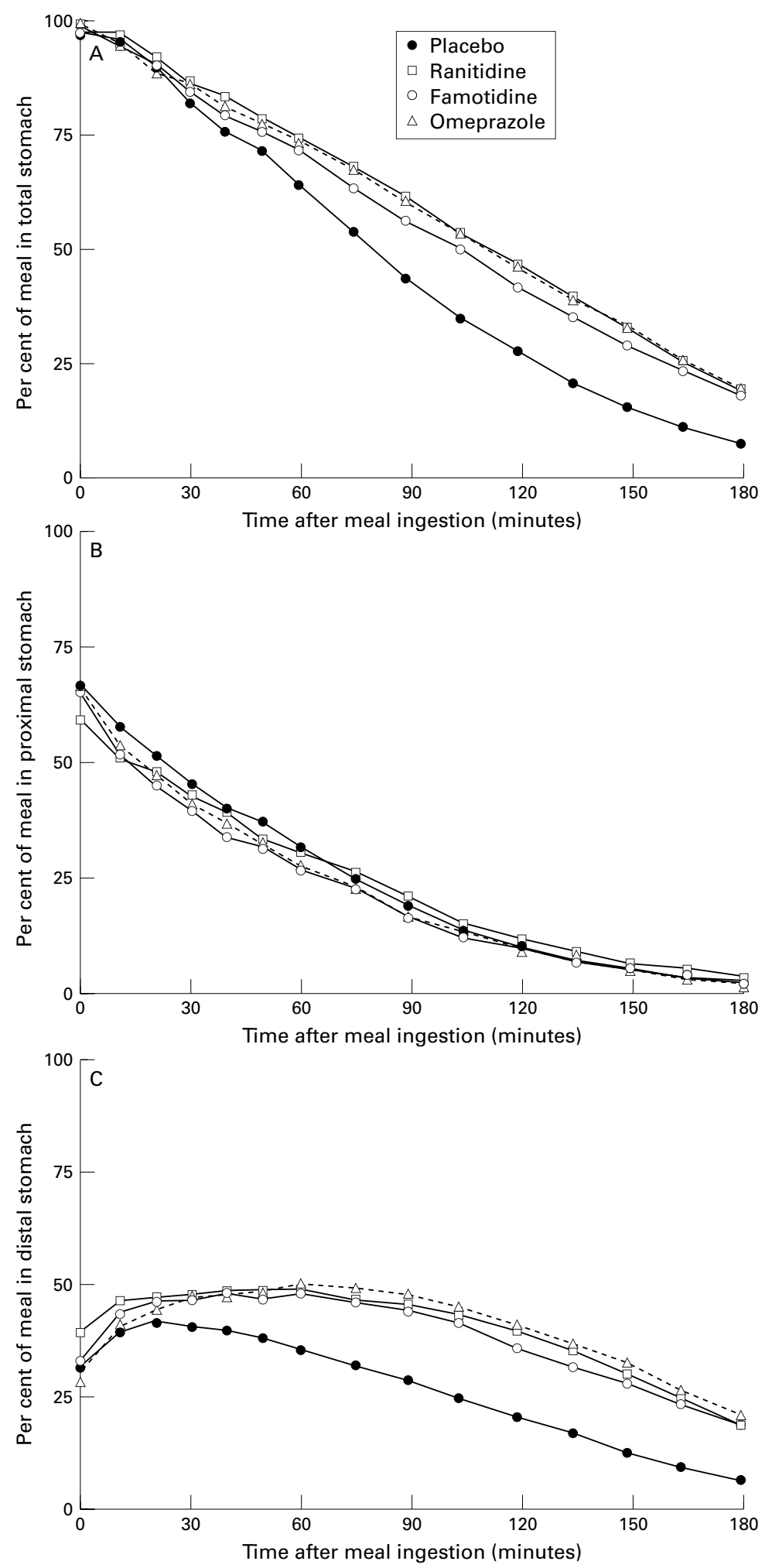

Figure 4 Effects of gastric acid suppressants on gastric emptying. (A) Total gastric emptying; (B) proximal gastric emptying; $(C)$ distal gastric emptying.

suppression, rather than a direct effect of the pharmacological agents, caused the increased phase III MMCs. A correlation between gastrointestinal secretion and motility has been described previously with increases in gastric acid secretion occurring when motility increases. ${ }^{31}$ Increased gastric acid secretion has been shown to be temporally related to the phase III portion of the MMC. ${ }^{32}$ It has been proposed that the regularity of the MMC may be governed by duodenal acidity; an alkaline duodenal $\mathrm{pH}$ is important for initiation of gastric phase III complexes. ${ }^{33}$ The short duration of fasting recording performed in this study (30 minutes) is a potential limitation; however, inhibition of gastric acid secretion has been observed to cause an increase in fasting gastric phase III activity in other studies with ranitidine $^{34}$ and omeprazole ${ }^{35}$ with more prolonged recording times. Conversely, increased gastric acid secretion has been associated with a decreased occurrence of MMCs. ${ }^{36}$

Postprandially, gastric emptying of solids was prolonged with ranitidine, an $\mathrm{H}_{2}$ receptor antagonist with cholinergic properties, ${ }^{17}{ }^{17}$ famotidine, an $\mathrm{H}_{2}$ receptor antagonist with minimal cholinergic effects, and omeprazole, a proton pump inhibitor without $\mathrm{H}_{2}$ receptor antagonist or cholinergic effects. These observations suggest that suppression of gastric acid per se resulted in delayed gastric emptying. There are several potential explanations for this effect. Firstly, decreased acid secretion and consequent pepsin deactivation may decrease hydrolysis of solids ${ }^{78}{ }^{10}$ resulting in larger food particles that would not pass easily through the pylorus. The delay in solid phase gastric emptying seen with omeprazole as reported here and in other studies, ${ }^{8738}$ is associated with normal liquid phase gastric emptying. ${ }^{38}$ Secondly, decreased gastric acid secretion is associated with an increase in serum gastrin. ${ }^{9}{ }^{38}$ Gastrin has been reported to delay gastric emptying despite producing an increase in antral contractility. ${ }^{10}$ Gastric acid suppression may affect gastric motility and emptying by other mechanisms also. Decreased acid secretion is accompanied by decreased fluid secretion; this might increase viscosity of the meals and alter gastric emptying. On the other hand, gastric acid per se has been reported to delay gastric emptying by activation of duodenal chemoreceptors. ${ }^{11} 12$ Therefore, decreased gastric acid secretion would be expected to alkalinise the stomach and duodenum and thus lessen the "braking action" of duodenal acid. ${ }^{11} 1239$ This would be expected to accelerate gastric emptying, ${ }^{39}{ }^{40}$ but such was not seen in this study.

Interestingly, antral contractility was increased postprandially with each of the gastric acid suppressants despite a slowing of gastric emptying. There are some concerns about catheter migration during meal periods when using ambulatory antral manometry ${ }^{20}$; with ingestion of the test meal and fundic relaxation, the catheter might be withdrawn so that the recording transducers are temporarily recording from a more proximal area, with less contractility. This potential problem, if it occurred, would be similar for each of the study arms and the change between the study arms in this crossover protocol should not be affected. Furthermore, the results of antral manometry are in agreement with those of DAS and EGG. Duodenal contractility, which potentially could inhibit gastric emptying, ${ }^{41}{ }^{42}$ was not changed during gastric acid suppression. The inverse 
relationship between antral contractility and gastric emptying has been observed previously with gastrin and the cholinergic agonist, bethanechol. ${ }^{10}$ Both of these agents increase antral motility, but do not accelerate gastric emptying. Delayed gastric emptying despite augmented antral contractility may be due to decreased hydrolysis of solids, increased pyloric tone, or uncoupling of antroduodenal contractions.

Dynamic antral scintigraphy images and quantifies the displacement of antral contents induced by antral contractions using rapid scintigraphic imaging. The results obtained with dynamic antral scintigraphy were similar to those obtained using antral manometry and electrogastrography. Correlation between these techniques has been reported previously. ${ }^{43-45}$ The increased antral contractility during gastric acid suppression was due to an increased amplitude, but not frequency, of contractions. This observation is similar to that recorded using antral manometry. Interestingly, although there was an increase in DAS amplitude, gastric emptying was delayed due to retention of the radiolabelled meal in the antrum and not in the proximal stomach.

The EGG power, which measures both amplitude and regularity of the recorded EGG signal, increases postprandially. ${ }^{26}$ The EGG postprandial power increase was greater with each of the three gastric acid suppressants.
This phenomenon is likely to be due to an increase in contractility (as shown with antral manometry and DAS), but could be affected by prolonged gastric distension due to longer gastric retention of the solid meal. ${ }^{26}$

$\mathrm{H}_{2}$ receptor antagonists may have effects on gastric motility independent of $\mathrm{H}_{2}$ receptor blockade and/or inhibition of gastric acid secretion. ${ }^{13} 3440$ We reported previously that ranitidine and nizatidine, but not famotidine or cimetidine, increased the amplitude of antral contractions in vitro. ${ }^{16}$ This effect was cholinergically mediated. This cholinergic property of some, but not all, of the $\mathrm{H}_{2}$ receptor antagonists has been reported in several other studies ${ }^{14} 15$ and may be due to inhibition of acetylcholinesterase, ${ }^{15} 17$ direct cholinergic agonist activity, ${ }^{16}$ or increased neuronal release of acetylcholine. ${ }^{46}$ Previous in vivo studies have found that ranitidine, but not cimetidine, accelerates gastric emptying. ${ }^{14}$ Other studies have suggested that ranitidine, but not cimetidine, increased antral contractility. ${ }^{5}$ Our study in normal human subjects shows increased antral contractility not only with ranitidine, but also with famotidine which has minimal cholinergic effects and also with the proton pump inhibitor, omeprazole. Thus the changes in gastric motility were seen irrespective of the method of gastric acid suppression, suggesting that the increased antral contractility might not be related to selective cholinergic properties of the compounds,
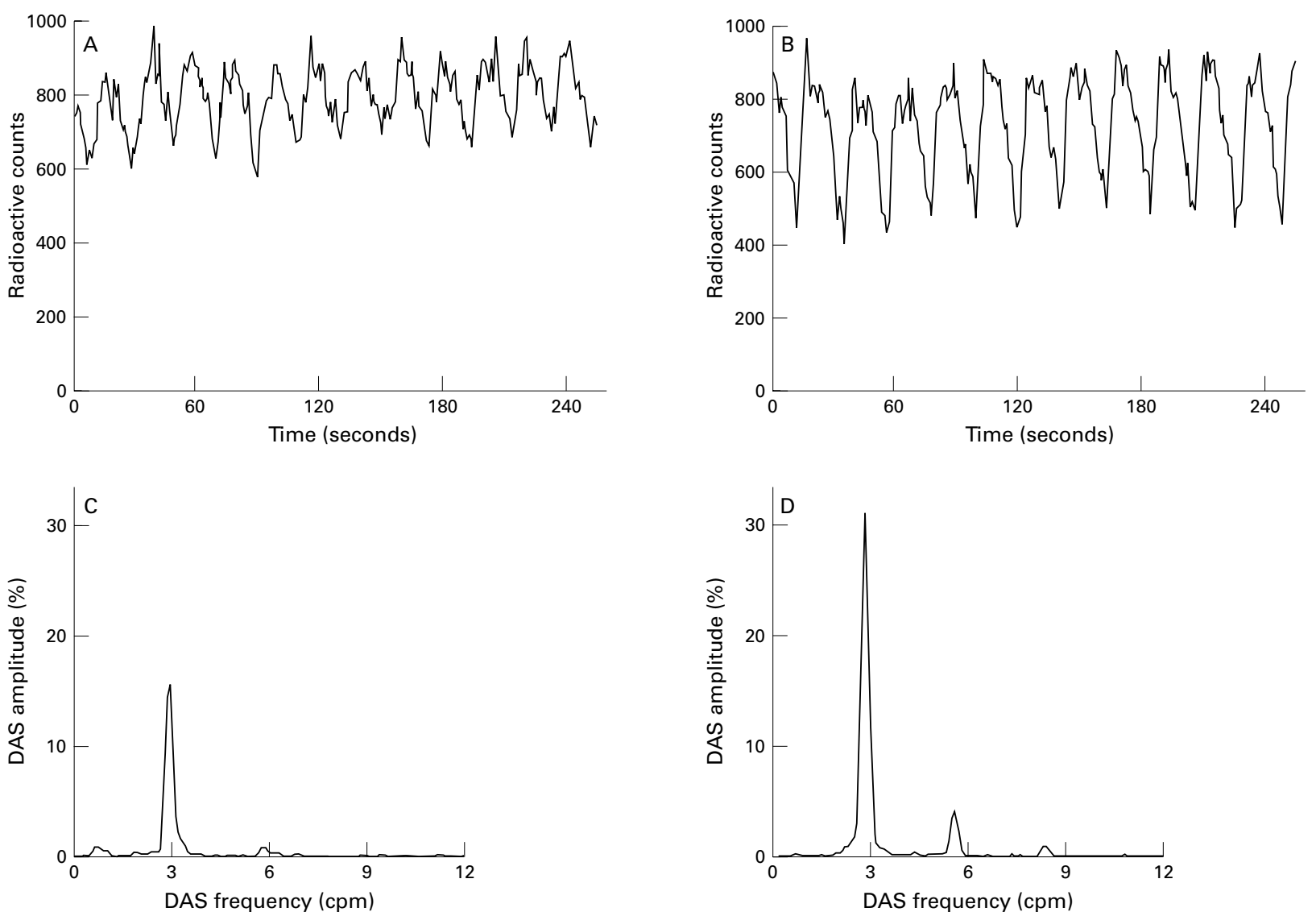

Figure 5 Dynamic antral scintigraphy. The time activity curve $(A)$ depicts radioactive counts in the mid-antral region versus time for the placebo arm for a subject 60 minutes after meal ingestion. The phasic counts represent the contracting antrum. (B) represents the same subject at the same time period after omeprazole therapy. There were increased phasic excursions of the radioactive counts in the omeprazole period as compared with placebo. With the fast Fourier transform analysis, the dominant frequency is represented by the peak with the highest amplitude $(C$ and $D)$. 
but rather, to the inhibitory effects of these compounds on gastric acid secretion.

These studies show that therapeutic doses of histamine $\mathrm{H}_{2}$ receptor antagonists administered intravenously and proton pump inhibitors administered orally delay gastric emptying. We cannot specifically address the degree of acid suppression achieved by these drug treatments, since an intragastric $\mathrm{pH}$ probe was not used during these studies. The study design used accepted therapeutic doses of the gastric acid suppressants, ones that are used clinically to achieve robust acid suppression. Using our clinical cut off for determining delayed gastric emptying of $>50 \%$ retention at two hours, ${ }^{47}$ $5 / 15$ of the subjects had delayed gastric emptying while in the ranitidine arm, 6/15 while in the famotidine arm, and $4 / 12$ while in the omeprazole arm, compared with only $1 / 15$ subjects in the placebo arm. Thus, the performance of the gastric emptying test on gastric acid suppressants may cause a clinically significant delay in gastric emptying. From a practical point of view, gastric emptying and motility studies should be interpreted cautiously in patients under treatment with gastric acid suppressants. Whether gastric emptying is slowed by oral administration of $\mathrm{H}_{2}$ receptor antagonists, ${ }^{6}$ and whether this slowing affects dyspeptic symptoms (early satiety, nausea, abdominal bloating) remains to be determined.

This research was funded in part by Glaxo Wellcome, Inc. Portions of this manuscript were presented at the 1996 American Gastroenterological Association Meeting and appeared in abstract form in Gastroenterology 1996;110:A731.

1 Houghton LA, Read RW. A comparative study of the effect of cimetidine and ranitidine on the rate of gastric emptying of liquid and solid test meals in man. Aliment Pharmacol Ther 1987;1:401-8.

2 Huscher C, Falchetti D, Besozzi F, et al. Ranitidine and total gastric emptying of liquids and solids. Curr Ther Res 1984; gastric emp

3 Logan RFA, Forrest JAH, McLoughlin GP, Lidgard G, Heading RC. Effect of cimetidine on serum gastrin and gastric emptying in man. Digestion 1978;18:220-6.

4 Parikh R, Sweetland J, Forster ER, Bedding AW, Farr SJ, Smith JTL. Ranitidine bismuth citrate and ranitidine do not affect gastric emptying of a radio-labelled liquid meal Br f Clin Pharmacol 1994;38:577-80.

5 Scarpignato C, Bertaccini G, Zimbaro G, Vitulo F Ranitidine delays gastric emptying of solids in man. $\mathrm{Br} \mathcal{F}$ Clin Pharmacol 1982;13:252-3.

6 Corinaldesi R, Scarpignato C, Galassi A, et al. Effect of ranitidine and cimetidine on gastric emptying of a mixed meal in man. Int f Clin Pharmacol 1984;22:498-501.

7 Kerrigan DD, Mangnall YF, Read NW, Johnson AG. Influence of acid-pepsin secretion on gastric emptying of solids in humans: studies with cimetidine. Gut 1991;32:1295-7.

8 Benini L, Castellani G, Bardelli E, et al. Omeprazole causes delay in gastric emptying of digestible meals. Dig Dis Sci delay in gastric em $1996 ; 41: 469-74$.

9 Forrest JAH, Heading RC, Park J, et al. Effect of histamine $\mathrm{H}_{2}$-receptor blockade on gastric emptying and serum gastrin in man. Scott Med F 1976;21:23-7.

10 Hamilton SG, Sheiner HJ, Quinlan MF. Continuous monitoring of the effect of pentagastrin on gastric emptying of solid food in man. Gut 1976;17:273-9.

11 Hunt JH, Knox MT. The slowing of gastric emptying by four strong acids and four weak acids. F Physiol 1972;222 $187-208$.

12 Cooke AR. Duodenal acidification: role of first part of duodenum in gastric emptying and secretion in dogs. Gastroenterology 1974;67:85-92.

13 Dubois A, Castell DO. Histamine $\mathrm{H}_{2}$-receptor involvement in the regulation of gastric emptying. Am $f$ Physiol in the regulation

14 Bertaccini G, Coruzzi G. Cholinergic-like effects of the new histamine $\mathrm{H}_{2}$-receptor antagonist ranitidine. Agents Actions 1982;12:168-71.

15 Mizumoto A, Fujimura M, Iwanaga Y, et al. Anticholinesterase activity of histamine $\mathrm{H}_{2}$-receptor antagonists in the dog: their possible role in gastric motor activity. Fournal of Gastrointestinal Motility 1990;2:273-80.

16 Parkman HP, Pagano AP, Ryan JP. Ranitidine and nizatidine stimulate antral smooth muscle contractility via an excitatory cholinergic mechanism [abstract]. Gastroenterology 1994;106:A553.

17 Kurosawa S, Nishilawa S, Kaneko M, Ro S, Yakabi K, Nakamura T. The contractile effects of $\mathrm{H} 2$ receptor antagonists nizatidine, ranitidine, famotidine and cimetidine on guinea pig gastric muscle [abstract]. Gastroenterology 1995;108:A634.

18 Physicians' desk reference. 49th edn. Montvale, NJ: Medical Economics Data Production Company, 1995.

19 Heiselman DE, Hulisz DT, Fricker R, Bredle DL, Black LD. Randomized comparison of gastric $\mathrm{pH}$ control with intermittent and continuous intravenous infusion of famotidine in ICU patients. Am f Gastroenterol 1995;90:277-9.

20 Holland R, Gallagher MD, Quigley EMM. An evaluation of an ambulatory manometry system in assessment of
antroduodenal motor activity. Dig Dis Sci 1996;41:1531-7.

21 Parkman HP, Harris AD, Fisher RS. Influence of age, gender, and menstrual cycle on the normal electrogastrogram. Am 7 Gastroenterol 1996;91:127-33.

22 Urbain J-LC, Maurer AH. The stomach. In: Wagner HN Jr, Szabo A, Buchanan JW, eds. Principles of nuclear medicine. Philadelphia: Saunders, 1995:916-29.

23 Miller MA, Parkman HP, Brown KL, et al. Comparison of scintigraphy and lactulose breath hydrogen test for assessment of orocecal transit: lactulose accelerates small bowel transit. Dig Dis Sci 1997;42:10-18.

24 Urbain J-LC, Charkes ND. Recent advances in gastric emptying scintigraphy. Semin Nucl Med 1995;25:318-25.

25 Kellow JE, Borody TJ, Phillips SF, Tucker RL, Haddad AC Human interdigestive motility: variations in patterns from esophagus to colon. Gastroenterology 1986;91:386-95.

26 Chen JDZ, McCallum RW. Clinical applications of electrogastrography. Am f Gastroenterol 1993;88:1324-36.

27 Siegel JA, Urbain J-L, Adler LP, et al. Biphasic nature of gastric emptying. Gut 1988;29:85-9.

28 Urbain J-L, Siegal JA, Charkes ND, Maurer AH, Malmud LS, Fisher RS. The two-component stomach: effects of meal particle size on fundal and antral emptying. Eur f Nucl 1989;15:254-9.

29 Urbain J-LC, Vekemans MC, Parkman H, et al. Characterization of gastric antral motility in functional dyspepsia using digital antral scintigraphy. F Nucl Med 1995;36:157986

30 Snedecor GW, Cochran WG. Statistical methods. 7th edn. Ames: Iowa State University Press, 1980.

31 Greenwood B, Davison JS. The relationship between gastrointestinal motility and secretion. Am $\mathcal{f}$ Physiol 1987;252:G1-7.

32 Vantrappen GR, Peeters TL, Janssens J. The secretory component of the interdigestive migrating complex in man. Scand $\mathcal{F}$ Gastroenterol 1979;14:663-7.

33 Woodtli W, Owyang C. Duodenal $\mathrm{pH}$ governs interdigestive motility in humans. Am f Physiol 1995;268:G146-52.

34 Bortolotti, M, Cucchiara S, Sarti P, Brunelli F, Del Campo $\mathrm{F}$, Barbara L. Interdigestive gastroduodenal motility in patients with ulcer-like dyspepsia: Effect of ranitidine. Hepatogastroenterology 1992;39:31-3.

35 Bortolotti M, Pinotti R, Sarti P, Barbara L. Interdigestive gastroduodenal motility in patients with active and inactive duodenal ulcer disease. Digestion 1989;44:95-100.

36 Bortolotti M, Barbara L. Interdigestive gastroduodenal motor activity in subjects with increased gastric acid secretion. Digestion 1988;41:156-60.

37 Atherton JC, Washington N, Bracewell MA, et al. Scintigraphic assessment of the intragastric distribution and gastric emptying of an encapsulated drug: the effect of feeding and of a proton pump inhibitor. Aliment Pharmacol Ther 1994;8:489-94

38 Rasmussen L, Oster-Jorgensen E, Qvist N, Kraglund K, Hovendal C, Pedersen SA. Short report: a double-blind placebo-controlled trial of omeprazole on characteristics of gastric emptying in healthy subjects. Aliment Pharmacol Ther 1991;5:85-9.

39 Forrest JAH, Fettes MR, McLoughlin GP, Heading RC. Effect of long-term cimetidine on gastric acid secretion, serum gastrin, and gastric emptying. Gut 1979;20:404-7.

40 Dubois A, Nompleggi D, Castell DO. Histamine $\mathrm{H}_{2}$ recepDubois A, Nompleggi D, Castell DO. Histamine $\mathrm{H}_{2}$ recep7 Physiol 1988;255:G767-71.

41 Rao SSC, Lu C, Schulze-Delrieu K. Duodenum as an immediate brake to gastric outflow: a videofluoroscopic and manometric assessment. Gastroenterology 1996;110: $740-7$.

42 Camilleri M, Malagelada J-R, Brown ML, Becker G, Zinsmeister AR. Relation between antral motility and gastric emptying of solids and liquids in humans. Am F Physiol 1985;249:G580-5

43 Urbain J-LC, VanCutsem E, Siegel JA, et al. Visualization and characterization of gastric contractions using a radionuclide technique. Am f Physiol 1990;259:G1062-7.

44 Jones K, Edelbrock M, Horowitz M, et al. Evaluation of antral motility in humans using manometry and scintigraphy. Gut 1995;37:643-8.

45 Knight LC, Parkman HP, Brown KL, et al. Delayed gastric emptying in normal women is associated with decreased antral contractility [abstract]. Gastroenterology 1996;110: A696.

46 Poli E, Coruzzi G, Bertaccini G. Ranitidine but not famotidine releases acetylcholine from the guinea pig myenteric plexus. Agents Actions 1990;30:191-4.

47 Parkman HP, Miller MA, Trate D, et al. Electrogastrography and gastric emptying scintigraphy are complementary for assessment of dyspepsia. I Clin Gastroenterol 1997;24:21419. 